\title{
AUTOFORMAÇÃO, PROFISSIONALIZAÇÃO DOCENTE E AS TECNOLOGIAS EDUCATIVAS NOS CURSOS DE PEDAGOGIA NA MODALIDADE À DISTÂNCIA DAS IES PÚBLICAS NO BRASIL
}

\author{
Rhanica Evelise Toledo Coutinho* \\ Joaquim José Jacinto Escola ${ }^{\dagger}$
}

\begin{abstract}
Resumo
$\mathrm{Na}$ pós-modernidade acreditamos que alguns docentes apresentam resistência ao uso das Tecnologias Educativas (TE). Busca-se identificar nos programas dos Cursos de Pedagogia na modalidade à distância das Instituições de Ensino Superior de ordem pública, inserções de temas transversais relacionados as TEs. Espera-se compreender como os conceitos de tecnologias vem sendo inseridos no processo de formação inicial, autoformação e profissionalização docente. Questiona-se: Existem conteúdos relacionados as Tecnologias da Educação inclusas nas ementas e disciplinas dos cursos de pedagogia das referidas IES? Dentre os sites dos cursos de pedagogia mapeados encontramos informações de modo a permitir uma avaliação transparente? Como as diferentes regiões do Brasil se comportam frente a essas questões? Como metodologia pautou-se nas Dimensões propostas por Novikoff, Levantamento do Estado do Conhecimento e pesquisa teórica do tipo mista. Destaca-se nos resultados que a maior concentração de IES que se utilizam das TEs encontram-se no Nordeste (13) e Sudeste (12), já região norte, possui apenas uma IES, justificando sua pouca expressividade no uso de TE. O termo "Tecnologia" que foi mencionado (88) vezes, denotando a existência de conteúdos de TE no material investigado, nota-se que a forma com que são disponibilizados, inviabilizam uma avaliação transparente.
\end{abstract}

Palavras chave: Autoformação docente; Tecnologias educativas; Pedagogia.

\section{AUTOFORMATION, TEACHING PROFESSIONALISM AND EDUCATIONAL TECHNOLOGIES IN THE PEDAGOGY COURSES IN THE DISTANCE MODE OF PUBLIC HEARTS IN BRAZIL}

\begin{abstract}
In postmodernity we believe that some professors are resistant to the use of Educational Technologies (ET). It seeks to identify in the programs of the Pedagogy Courses in the distance modality of the public Higher Education Institutions (HEI), insertions of transversal themes related to the ETs. Looking for understand how the concepts of technologies were inserted in the process of formation, self-training and teaching professionalization. Are there any contents related to the ET included in the subjects of these pedagogical courses? Between sites of mapped pedagogy courses is possible to find information in order to allow transparent evaluation? How different regions of Brazil behave in front of these issues? The methodology was based on the Dimensions proposed by Novikoff, Survey of the State of Knowledge and theoretical research of the mixed type. Results emphasizes that the highest concentration of HEIs using ETs are located in the Northeast (13) and Southeast (12), whereas in the north there is only one HEI, justifying this little expressiveness in the use of ET. The term "Technology" was mentioned (88) times, denoting the existence of ET contents in the material investigated, however the mode in which they are made available, makes a transparent evaluation impossible. Keywords: Teacher self-training; Educational technologies; Pedagogy.

\footnotetext{
* Doutoranda em Ciências da Educação - UTAD/Portugal. Docente do Centro Universitário de Volta Redonda - UniFOA.

${ }^{\dagger}$ Doutor em Educação. Docente da Universidade de Trás-os-Montes- Alta Douro.
} 


\section{Introdução}

Mesmo na pós-modernidade acreditamos que alguns docentes apresentam certa resistência quanto ao uso das Tecnologias Educativas (TE), e, em outros casos, percebemos a existências daqueles se utilizam das TEs, objeto deste estudo, em seu processo de autoformação e profissionalização sem mesmo perceber.

Busca-se identificar nos programas dos cursos de pedagogia na modalidade à distância das Instituições de Ensino Superior (IES) de ordem pública a inserções de temas transversais relacionados as TEs.

Espera-se compreender como os conceitos de tecnologias vem sendo sedimentados no processo de formação inicial, autoformação e profissionalização docente, em seguida desejamos promover reflexões sobre a importância do uso das tecnologias para educação de forma integral e constante.

Nesse sentido, questiona-se: Existem conteúdos relacionados as Tecnologias Educativas inclusas nas ementas, matriz curricular e/ou disciplinas dos cursos de pedagogia das referidas IES? Dentre os sites dos cursos de pedagogia encontramos informações de modo a permitir uma avaliação transparente? Como as diferentes regiões do Brasil se comportam frente a essas questões?

Acreditamos que existem diferenças quanto a inserção das Tecnologias Educativas entre as cinco regiões de Brasil (norte, nordeste, centro oeste, sudeste e sul) e pressupomos que as ementas não contemplam a inserção de temáticas atreladas as Tecnologias Educativas na mesma rapidez com que esse conceito vem sendo expandido. O usuário de tecnologias torna-se um agente criador e transformador, o que justifica a inserção desse conteúdo de forma transversal e interdisciplinar nos programas de pedagogia (CASTELLS, 2000).

Trata-se de uma pesquisa teórica do tipo mista (CRESWELL, 2007), pautada nas Dimensões propostas por Novikoff (2010), que consiste em um modo de organizar o pensamento científico em cinco etapas, sendo elas: Dimensão Epistemológica onde se aborda os conceitos iniciais, delimita-se o objeto de estudo, problematização, objetivo geral e específico, pressuposto teórico, justificativa e delimitação do tipo de pesquisa; Dimensão Teórica, apresenta a ancoragem teórica do estudo; Dimensão Técnica que delineia o caminho metodológico utilizado na pesquisa; Dimensão Morfológica, onde 
são apresentados os dados e a Dimensão Analítica-conclusiva, apresenta as respostas dos questionamentos, a discussão entre resultados e teorias.

Foi realizada uma revisão bibliográfica para a fundamentação teórica, seguida de um Levantamento do Estado do Conhecimento (ROMANOWSKI; ENS, 2006) visando identificar os indícios da inserção de Tecnologias para Educação nos programas dos cursos de Pedagogia. Romanowski e Ens (2006) diferencia o "Estado do Conhecimento" do "Estado da Arte", uma vez o primeiro consiste em investigação realizada por meio de um recorte temporal e de espaço com objetivo de verificar nesse contexto apenas os termos investigados.

\section{Profissionalização Docente}

As reflexões sobre a profissionalização docente vêm permeando as discussões acadêmicas no contexto nacional e internacional, trazendo à tona, múltiplas análises sobre o desenvolvimento profissional docente, principalmente no que tange a necessidade do "[...] esforço da categoria para efetivar uma mudança tanto no trabalho pedagógico que desenvolve, quanto na sua posição na sociedade" (VEIGA, 1998, p. 76).

Esse movimento busca tratar do que compartilha Libâneo (1998) ao definir como profissionalidade, um neologismo usado por ele e por Rios (1997), que aborda a importância da preservação da identidade docente em sua essência, ou seja, um exercício onde a liberdade política e intelectual sejam os pilares de nova cultura profissional.

Nesse contexto de mudanças culturais Papi $(2005$, p. 1) afirma ser "necessários para que o coletivo dos professores desenvolva, desde a formação inicial, uma nova cultura profissional, estando mais próximo de alcançar as aspirações de maior credibilidade e dignidade profissional", a autora enfatiza também mediante a complexa realidade vivida pelos docentes o enfoque cultural atrelado a esfera educacional, âmbito este, respaldado por valores, crenças, ritos e concepções que se reestabelecem por meio de uma trajetória histórica que lhe atribui um prisma de transformações (TEIXEIRA, 1999).

Nas palavras de Papi (2005, p. 2) o "desenvolvimento da profissionalidade, assume relevante papel na profissionalização docente, o enfoque cultural, que tem merecido destaque singular no âmbito educacional, tendo em vista a complexidade da realidade e a busca da sua compreensão", uma vez que a cultura profissional destaca-se, 
por sua relevância e influência, quanto sua função estruturante e comportamental, que deverá permear o perfil do profissional docente habitualmente (FORQUIN, 1993).

Sabemos que o estudante e/ou docente que demonstrar compreender as características relativas à sua formação, assim como, o entendimento da conjuntura do seu meio profissional, poderá estabelecer uma interface entre o seu desenvolvimento profissional, as questões escolares, humanas e sociais.

A necessidade de se criar uma cultura profissional docente a partir da formação inicial, está atrelada ao exercício das práticas inerente a formação, trata-se que uma questão de aprendizagem (IMBERNÓN, 1998).

Uma nova cultura profissional docente pode emergir interiormente e exteriormente a profissão, que neste caso deverá ser sustentada pelo bom desenvolvimento da carreira docente mantendo-se ainda o lugar do idealismo escolar que em sua essência traz valores e aspectos positivos (NÓVOA, 1995).

A habilidade desenvolvida pelos docentes visando o uso de Tecnologias Educativas tornou-se uma demanda atual, inerente ao exercício da profissão docente, daí a necessidade do professor se preocupar com uma formação voltada para a um contexto profissional, visando atender a comunidade escolar, mas que também possa ser um ícone de profissional na sociedade, constituindo assim, uma nova identidade (NÓVOA, 1995 apud PAPI, 2005).

Vale lembrar, que as condições de trabalho poderão influenciar consideravelmente esses docentes, podendo até mesmo ser um dos obstáculos frente ao desenvolvimento desses profissionais que de um modo geral vivenciam uma cultura individualista e pouco cooperativa (LISTON; ZEICHNER, 1997).

Para Imbernón (1998) se trata de um tipo de cultura que não enaltece a colegialidade, ou seja, um caminho para o estabelecimento de vínculos entre os professores. Nesse sentido, vale lembrar que as Tecnologias da Informação e Comunicação (TICs) podem ser um instrumento facilitador, estreitando o espaço/tempo dos envolvidos que poderão certamente aprender novos caminhos deixando de apenas reproduzir processos e estilos, evitando assim, perdurar com as práticas tradicionais e rotineiras que não priorizam as demandas profissionais, para Contreras (2002, p. 270) esse tipo de cultura "[...] é produto histórico do controle, da burocratização e da desprofissonalização".

Existe por grande parte desses profissionais, o comodismo que se estabelece por meio de repetição padrões, não percebemos a existência do desconforto que provoca RPI Revista de Pesquisa Interdisciplinar, Cajazeiras, v. 1, n. 1, 111-125, jan/jul. de 2017. 
a evolução e que acompanha as mudanças destinadas ao progresso dessa classe (PÉREZ GÓMEZ, 2001).

Papi (2005, p. 6) relata a seguir em seus resultados de investigação que

Com relação à Cultura Profissional veiculada, percebemos que os pesquisados, em sua maioria, têm dificuldade em perceber que as exigências feitas durante o curso constituem elementos necessários para atender à complexidade da prática docente, isto é, que são importantes para a sua formação profissional.

Tal afirmativa traz à tona a necessidade de se incutir na formação inicial, ponderações sobre a postura crítica de um profissional e sua relação com as questões éticas inerentes a sua profissão, essa pode ser uma forma de estimular os acadêmicos a tomarem consciência da responsabilidade que devem ter com relação a sua formação, evitando dessa forma, que os estudantes se coloquem na condição daqueles que apenas cumprem determinações.

A interação entre o pensamento e ação, resultam na aprendizagem, inserindo o aprendiz na construção de conhecimento e da sociabilidade (PIAGET; SCHRAMM; LENARDON, 1977). Em sua investigação com docentes e egressos de cursos de pedagogia Papi $(2005$, p. 7) revela que "a construção da identidade dos professores e da sua profissionalidade pode estar sendo comprometida".

A partir de tais constatações, entende-se que há necessidade de se repensar o processo de formação de professores, devemos encontrar um caminho onde a articulação entre a teoria e a prática, estejam presentes em todo o percurso, desde a formação inicial até a formação continuada, e nesse sentido, nos atentar para que esse processo ocorra de forma inovadora, não pragmática, mas investigativa, Papi (2005, p. 7-8) afirma que

O desenvolvimento da colegialidade entre os professores é fator imprescindível para o desenvolvimento de uma prática pedagógica que enseje mudanças, constituindo-se em elemento da cultura profissional. Entretanto, a análise realizada evidenciou a ausência, entre os sujeitos da pesquisa, de um conceito de colegialidade profissional. Eles têm dificuldade em fazer referência a um trabalho cooperativo que, além de ser fruto de sua própria iniciativa, seja uma necessidade percebida pelos profissionais, e não uma forma de trabalho imposta por outras instâncias.

Daí a importância da difusão do conceito de colegialidade nos cenários de aprendizagens dos vindouros docentes que deverão primar pelos princípios norteadores do trabalho profissional, destacando-se dentre eles a ética, como princípio basilar desses 
futuros agentes de mudanças, que se manterão em crescimento por meio da formação continuada que nunca deverá ser enfatizada em detrimento a formação inicial, a qual é essencial e basilar.

Vale destacar que o processo de formação inicial deve ser desenvolvido de forma plena e consolidada em diversos aspectos, dentre eles: pedagógico, cultural, científico e social (PAPI, 2005).

Nesse sentido, percebe-se nos resultados da pesquisa desenvolvida por Papi (2005) que a abordagem sobre a organização da categoria docente, provavelmente não foi privilegiada pela formação, porque os pesquisados demonstram desconhecer o fato de que os professores não constituem uma categoria formalmente organizada, principalmente porque desconhecem que não dispõem de um Conselho Profissional, organização que pode se fazer necessária não apenas porque as outras profissões a têm, mas porque, de alguma forma, precisa-se construir algo para que a classe docente seja mais respeitada. Imbernón (2000, p. 65),

$\mathrm{Na}$ formação para a aquisição do conhecimento profissional pedagógico básico, deve haver lugar para a mudança, e não temos de temer a utopia. Muitas coisas que hoje são realidade pareciam utópicas há apenas alguns anos. A formação do professor de qualquer etapa educativa não pode permitir que as tradições e costumes, que se perpetuaram com o passar do tempo, impeçam que se desenvolva e se ponha em prática uma consciência crítica nem que dificultem a geração de novas alternativas que tornem possível uma melhoria da profissão.

Dessa forma, torna-se primordial que as IES que formam docentes deixem claro seus objetivos, quanto a formação de profissionais com competências e habilidades que os permitam solucionar de forma criatividade situações inusitadas no contexto da prática profissional, contudo, o engajamento desses profissionais deve ser estimulado.

\section{Autoformação Docente}

O campo da educação se encontra assim confrontada com a supremacia dessa ideologia cientificista (NICOLESCU, 1996, p. 21) que se impõe mundialmente, em nome de referências científicas ultrapassadas, com o apoio das tecnologias ocidentais da informação. Face a esses desafios, não podemos deixar de nos sentir individualmente muito fracos (GALVANI, 2002 p.1) 
Para iniciar uma reflexão em relação a autoformação docente, necessita-se pensar sobre esse processo a partir da transdisciplinaridade eixo teórico que servirá como alicerce mediante ao uso da autoformação desenvolvida a partir do docente. Pela voz de Maldonado-Torres (2016, p. 19) pode-se compreender que

transdisciplinaridade, neste contexto, significa, em primeiro lugar, a necessidade de reconhecer imperativos e lógicas mais amplas do que as disciplinas que encontram sua orientação própria e em relação às quais elas mesmas e seus métodos podem se destruir e se reconstruir de forma distinta.

O conceito acima abordado torna-se antagônico ao que chamamos de interdisciplinaridade que sob a luz de Japiassu (1976, p.74) "a interdisciplinaridade caracteriza-se pela intensidade das trocas entre os especialistas e pelo grau de interação real das disciplinas no interior de um mesmo projeto de pesquisa", conceito esse que está dentro da realidade do que se desenvolve no contexto da formação docente.

Nesse sentido, a autoformação docente está muito próxima ao processo transdisciplinar, uma vez que, pode-se compreender a autorfomação em uma parte do processo de formação, ou seja, ela não poderá ser compreendida como um fator que esteja a ermo. Galvani (2002, p.1) afirma que "não se trata de egoformação propalada por uma visão individualista", portanto, consiste em um procedimento tripolar, sustentado e desenvolvido a partir de três pólos que se constituem em: "si (autoformação), os outros (hetero-formação) e as coisas (eco-formação)" (GALVANI, 2002, p. 1).

Pode-se compreender o pólo hétero como lugar onde ocorre o processo "da educação, das influências sociais herdadas da família, do meio social e da cultura, das ações de formação inicial e contínua, etc.” (GALVANI, 2002, p. 2), sendo a mesma deliberada e classificada de forma heterônima pelo meio ambiente cultural.

Quanto a constituição do pólo eco percebe-se que ele surge a partir das influências "físicas, climáticas, e das interações físico-corporais que dão forma à pessoa" (GALVANI, 2002, p. 3), surgindo dessa forma, uma dimensão simbólica. Neste contexto o meio ambiente físico a partir de sua diversidade (florestas, desertos, países, temperados, metrópoles urbanas, etc.) torna-se uma forte influência nas culturas humanas, assim como também sobre imaginário pessoal, que possui e que visa orientar “o sentido dado à experiência vivida" (GALVANI, 2002, p. 3).

Constata-se que os polos eco e hetero caracterizam as tomadas de consciência e as reações do indivíduo frente as influências físicas e sociais herdadas, sustentadas a 
partir do "conceito de acoplamentos estruturais" de Varela (1989), dessa forma, o conceito de autoformação pode ser entendido como a tomada de consciência do indivíduo sobre sua própria vida, o que Varela (1989) intitula como "fechamento operacional".

Compreender a si mesmo e como ocorre a inteiração de si com o meio torna-se o alicerce do processo de autoformação docente, conforme disse Galvani (2002, p 3):

\footnotetext{
A autoformação é um processo paradoxal que se alimenta de suas dependências. Ela é constituída pela tomada de consciência e de retroação sobre as influencias heteroformativas e ecoformativas. Assim, a autoformação ultrapassa, integrando-os, os limites da educação entendida transmissão-aquisição de saberes e de comportamentos.
}

Sendo assim, torna-se impossível pensar e autoformação sem a articulação consigo e com o meio, necessita-se compreender o processo de articulação do retorno, ou seja, a interação e a reflexão se mesclam neste processo. Neste contexto Galavi (2002, p.4) destaca que a "autoformação se declina então em três processos de retroação: retroação de si sobre si (subjetivação), retroação sobre o meio ambiente social (socialização) e retroação sobre o meio ambiente físico (ecologização)". O que nos leva a acreditar na autoformação docente como uma aliada no processo da profissionalização docente.

\section{Apresentação de dados e Resultados}

\section{Cursos de Pedagogia no Brasil}

O Ministério da Educação no Brasil, afirma em seu portal que os cursos de pedagogia deverão priorizar formação de professor, nesse sentido, o órgão propõe a publicação de um novo instrumento de autorização dos cursos de pedagogia, onde se destaca como principal exigência que $70 \%$ da carga horária do curso seja destinada à formação de professores em uma perspectiva teórica e prática (BRASIL, 2016).

Segundo o portal do e-MEC (BRASIL, 2016) existem 1.833 cursos de Licenciatura em Pedagogia em atividade, ofertados por Instituições de Ensino Superior públicas e privadas no Brasil. Divididos na modalidade presencial e à distância conforme apresentado na Tabela 1. 


\begin{tabular}{l|c|c}
\hline \multirow{2}{*}{ Modalidade } & \multicolumn{2}{|c}{ e-MEC Cursos de Pedagogia } \\
\cline { 2 - 3 } & IES Públicas & IES Privadas \\
\hline Presencial & 464 & 1.247 \\
\hline À Distância & 38 & 85 \\
\hline Total & \multicolumn{2}{|c|}{$\mathbf{1 . 8 3 3}$} \\
\hline
\end{tabular}

Tabela 1: Curso de Pedagogia no Brasil

Fonte: Portal e-MEC (2016)

O então Ministro da Educação Fernando Haddad afirma que "Embora a maioria dos professores sejam formados em cursos de pedagogia, esses cursos, regra geral, não estão estruturados para formar professores, já que têm baixa carga horária destinada a esse fim", de acordo com o portal será proposto um aumento na carga horária e um levantamento da bibliografia para que seja verificado se a mesma está voltada para a formação docente (BRASIL, 2016, s/p).

Diante do contexto histórico do curso de Pedagogia no Brasil, sabemos que se trata de um processo complexo e permeado por querelas que despertaram originalmente debates sobre o perfil do profissional a ser formado, que ainda perduram mesmo no decorrer de longos anos. Aquino (2007, p. 41) ainda destaca o "questionamento do próprio estatuto epistemológico da ciência pedagógica. O processo responsável por sua legitimação vem se constituindo num emaranhado de propostas divergentes, contrastantes, muitas vezes, inconciliáveis", o que de certa forma ainda dialoga com a realidade na qual se encontra o curso no Brasil. Para Libâneo (2001, p. 22)

\begin{abstract}
A pedagogia é uma área de conhecimento que investiga a realidade educativa no geral e no particular, mediante conhecimentos científicos, filosóficos e técnicos profissionais buscando explicitação de objetivos e formas de intervenção metodológicas e organizativas em instâncias da atividade educativa implicada no processo de transmissão/apropriação ativa de saberes e modo de ação.
\end{abstract}

Daí a importância de se mapear o desenvolvimento e as adequações deste curso tão relevante, assim como cabe também refletir sobre as adequações necessárias mediante as demandas da comunidade escolar e da sociedade. A Tabela 2 apresenta detalhadamente as categorias e quantidade de IES por região do Brasil.

\begin{tabular}{l|c|c|c|c|c|c}
\hline \multicolumn{7}{c}{ Categorias Institucionais das IES Públicas } \\
& Sul & Sudeste & $\begin{array}{c}\text { Centro- } \\
\text { Oeste }\end{array}$ & Norte & Nordeste & Total \\
\hline Universidade Federal & $\mathbf{4}$ & $\mathbf{9}$ & $\mathbf{4}$ & $\mathbf{1}$ & $\mathbf{9}$ & $\mathbf{2 7}$ \\
\hline Universidade Estadual & $\mathbf{4}$ & $\mathbf{2}$ & & & $\mathbf{3}$ & $\mathbf{9}$ \\
\hline
\end{tabular}

RPI Revista de Pesquisa Interdisciplinar, Cajazeiras, v. 1, n. 1, 111-125, jan/jul. de 2017. 


\begin{tabular}{l|c|c|c|c|c|c}
\hline Universidade Municipal & & $\mathbf{1}$ & & & & $\mathbf{1}$ \\
\hline Instituto Federal & & & & & $\mathbf{1}$ & $\mathbf{1}$ \\
\hline Total por Região/Geral & $\mathbf{8}$ & $\mathbf{1 2}$ & $\mathbf{4}$ & $\mathbf{1}$ & $\mathbf{1 3}$ & $\mathbf{3 8}$ \\
\hline
\end{tabular}

Tabela 2: Cursos de Pedagogia na modalidade a distância em IES públicas por região e tipo Fonte: Portal e-MEC (2016)

Nos chamou a atenção o fato de encontrar dentre as IES que ofertam o curso de Pedagogia na modalidade à distância apenas um Instituto Federal e uma Universidade Municipal, conforme apresentado na Tabela 2 a seguir.

Compartilhamento de Informações sobre o Projeto Pedagógico, Matriz ou ementa dos Cursos de
Pedagogia

Tabela 2: Mapeamento dos conteúdos do Cursos de Pedagogia Fonte: Portal e-MEC (2016)

Uma questão que chamou atenção neste recorte do estudo, foi ausência nos textos de termos como ciberespaço, game, linguagem virtual, online e mídias sociais. A ausência do termo mídias sociais chama a atenção pelo fato desse conceito estar presente no cotidiano de grande parte dos números de estudantes, acreditamos que principalmente daqueles que optam pelo ensino a distância.

Com relação aos números de IES que mencionaram em seus textos os indexadores atrelados ao ensino da tecnologia, foi possível identificar com relação aos números encontrados que existe um destaque para a região do Nordeste onde são identificados quarenta e sete (47) termos vinculados a Tecnologias Educativas, mas nota-se também uma proximidade entre o Nordeste, a região Sul com quarenta e três (43) termos e a região Sudeste com quarenta e um (41). Já as outras duas regiões denotam uma proximidade numérica entre elas, mas, que destoa das regiões acima mencionadas, onde a região Centro-oeste apresenta sete (7) e a região Norte seis (6) 
indexadores. A Tabela 4 apresentada a seguir detalhadamente os termos e os quantitativos encontrados. 


\begin{tabular}{l|c}
\hline \multicolumn{1}{c|}{ Indexadores } & $\begin{array}{c}\text { Número de } \\
\text { Inserções }\end{array}$ \\
\hline $\begin{array}{l}\text { Alfabetização Digital; Correio Eletrônico; Educação à Distância; Educação Aberta; } \\
\text { Ensino à Distância; Letramento Digital; Linguagem Informacional; Mediático; Netiqueta; } \\
\text { Power Point; Recursos Computacionais; Telemática; Videoconferência; Web; Word. }\end{array}$ & $\mathbf{0 1}$ \\
\hline $\begin{array}{l}\text { Aplicativos; Editor de Texto; Jogos; Informática Educativa; Informática em Educação; } \\
\text { Multimídia; Sistemas Operacionais; Vídeo. }\end{array}$ & $\mathbf{0 2}$ \\
\hline Ciência, Tecnologia e Sociedade; Cultura das Mídias; Moodle; TICs. & $\mathbf{0 3}$ \\
\hline Ambiente Virtual de Aprendizagem & $\mathbf{0 4}$ \\
\hline CTS - Ciência, Tecnologia e Sociedade & $\mathbf{0 5}$ \\
\hline Computador; Internet; Meios de Comunicação; Software & $\mathbf{0 6}$ \\
\hline Mídias & $\mathbf{0 7}$ \\
\hline Virtual & $\mathbf{0 8}$ \\
\hline Informática & $\mathbf{1 7}$ \\
\hline Novas Tecnologias & $\mathbf{1 8}$ \\
\hline EAD & $\mathbf{2 2}$ \\
\hline Comunicação & $\mathbf{3 4}$ \\
\hline Tecnologia & $\mathbf{8 8}$ \\
\hline
\end{tabular}

Tabela 4: Indexadores inerentes ao campo da Tecnologia da Educação.

Fonte: Portal e-MEC (2016)

Vale detalhar as informações sobre o termo "Tecnologia" que foi mencionado oitenta e oito (88) vezes, sendo mencionado ao menos uma vez em seis (6) IES no Sul; nove (9) IES no Sudeste; duas (2) IES no Centro-oeste; uma (1) IES no Norte e onze (11) no Nordeste do Brasil. Mais uma vez a região Nordeste se destaca.

Foram encontrados um total de 55 disciplinas que de alguma forma continham conteúdos que dialogam com a Tecnologia da Educação, destas cinco (5) eram ofertadas como disciplinas optativas, ou seja, aquela disciplina em que o discente deve cumprir, mas, deverá escolher entre outras a alternativas.

\section{Considerações Finais}

Foi identificado a existência de conteúdos de TEs no material investigado, porém, a forma como são disponibilizados, inviabilizam uma avaliação transparente, visto que em alguns casos, faltam as descrições detalhadas dos conteúdos, ou não estão diretamente ligados ao ensino de Tecnologias Educativas. Destaca-se a região Nordeste que de acordo com os indicadores, fomenta as Tecnologias Educativas no ensino de Pedagogia, enquanto a região Norte possui apenas uma IES que oferta o ensino superior de Pedagogia na modalidade a distância, justificando sua pouca expressividade quanto ao uso de Tecnologias Educativas na formação e profissionalização docente. 
Das 1.833 IES que ofertam o curso de Pedagogia, 38 se encontram na modalidade a distância. Dessas, 27 são Universidades Federais, 9 Estaduais e 1 Municipal. Foi identificado um Instituto Federal. Do número total de IES a maior concentração ocorre na região Nordeste com treze (13) e no Sudeste com doze (12). Quantos as outras regiões existem oito (8) no Sul, quatro (4) no centro-oeste e apenas uma (1) na região Norte.

Com relação ao compartilhamento de informações sobre o Projeto Pedagógico do Curso (PPC), matriz curricular ou ementa, das 39 IES, 33 disponibilizaram algum tipo de conteúdo, 4 não apresentaram nenhuma informação e apenas uma disponibilizou um (1) conteúdo, mas que estava com seu arquivo corrompido, impossibilitando acesso as informações.

Com relação aos números de IES que mencionaram em seus textos os indexadores atrelados ao ensino da tecnologia, foi possível identificar com relação aos números encontrados que existe um destaque para a região do Nordeste onde são identificados quarenta e sete (47) termos, mas nota-se também uma proximidade entre o Nordeste, a região Sul com quarenta e três (43) termos e a região Sudeste com quarenta e um (41). Já as outras duas regiões denotam uma proximidade numérica entre elas, mas, que destoam das regiões acima mencionadas, onde a região Centro-oeste apresenta sete (7) e a região Norte seis (6) indexadores.

Vale detalhar as informações sobre o termo "Tecnologia" que foi mencionado oitenta e oito (88) vezes, sendo mencionado ao menos uma vez em seis (6) IES no Sul; nove (9) IES no Sudeste; duas (2) IES no Centro-oeste; uma (1) IES no Norte e onze (11) no Nordeste do Brasil, o que deixa a Nordeste mais uma vez em destaca.

Foram encontrados um total de 55 disciplinas que de alguma forma continham conteúdos que dialogam com a Tecnologia da Educação, destas, cinco (5) eram ofertadas como disciplinas optativas, ou seja, aquela disciplina em que o discente deve cumprir, mas, deverá escolher entre outras a alternativas, resultado que minimiza ainda a possibilidade de se optar pelas TEs.

Os resultados mostram uma lacuna quanto a inserção do termo Tecnologia Educativa nas ementas das IES pesquisadas nesse estudo, o que nos leva a desdobrar esse mesmo estudo de ementas do curso de pedagogia agora nos cenários das IES públicas presenciais e das privadas presenciais e na modalidade a distância visando ampliar a análise desse cenário. 
Referências

AQUINO, Thais Lobosque. A música na formação inicial do pedagogo: embates e contradições em cursos regulares de Pedagogia da região Centro-Oeste. 2007, 216p. Dissertação (Mestrado em Educação) - Goiás: Universidade Federal de Goiás, 2007.

Disponível:https://repositorio.bc.ufg.br/tede/bitstream/tde/2027/1/Dissertathaislobosque .pdf. Acesso: 23/07/2016.

BRASIL, Ministério da Educação. Cursos de pedagogia deverão priorizar formação de professor. Formação de jovens e oportunidades de trabalho são temas de seminário em Brasília. Disponível <http://portal.mec.gov.br/component/tags/tag/33164〉. Acesso: 20/07/2016.

CASTELLS, Manuel. A sociedade em rede. São Paulo: Paz e Terra, 2000. 639p.

CONTRERAS, José. A autonomia de professores. Tradução de Sandra Trabuco Valenzuela. São Paulo: Cortez, 2002. 296p.

CRESWELL, John W. Projeto de Pesquisa: Métodos Qualitativo, Quantitativo e Misto. 2. ed., Porto Alegre: Artmed, 2007. 296p.

E-MEC, Portal de Instituições e Cursos de Educação Superior. Instituições de Educação Superior e Cursos Cadastrados. Disponível: http://emec.mec.gov.br/. Acesso: 01/07/2016.

FORQUIN, J. C. Escola e Cultura: as bases sociais e epistemológicas do conhecimento escolar. Tradução de Guacira Lopes Louro. Porto Alegre:Artes Médicas, 1993. 208p.

GALVANI, Pascal. A Autoformação, uma perspectiva transpessoal, transdisciplinar e transcultural. In: Educação e Transdisciplinaridade II. São Paulo, Triom, 2002.

IMBERNÓN, Francisco. Formação docente e profissional: formar-se para a mudança e a incerteza. São Paulo: Cortez, 2000. 128p. IMBERNÓN, Francisco. La formación y el desarrollo profesional del profesorado: hacia uma nueva cultura profesional. 3. ed. Barcelona: Editorial Graó, 1998. 157p.

JAPIASSU, Hilton. Interdisciplinaridade e patologia do saber. Rio de Janeiro: Imago Editora, 1976. 217p.

LIBÂNEO, José Carlos. Adeus professor, adeus professora?: novas exigências educacionais e profissão docente. São Paulo: Cortez, 1998.

LIBÂNEO, José Carlos. Organização e gestão da escola: teoria e prática. Goiânia: Alternativa, 2001. 313p. 
LISTON, Daniel P.; ZEICHNER, Kenneth M. Formación del profesorado y condiciones sociales de la escolarización. Tradução de Pablo Manzano. 2. ed. Madri: Morata, 1997. 280p.

MALDONADO-TORRES, Nelson. Transdisciplinaridade e decolonialidade. Revista Sociedade e Estado. Vol. 31, n. 1, p. 75-97, 2016. Disponível:

http://www.scielo.br/pdf/se/v31n1/0102-6992-se-31-01-00075.pdf. Acesso: 07/09/2016.

MARCELO GARCIA, C. M. Formação de professores: para uma mudança educativa. Porto: Porto Editora, 1999.

NICOLESCU, Basarab. O manifesto da transdisciplinaridade. Tradução: Lúcia Pereira de Souza. São Paulo: Trion Editora, 1999.

NOVIKOFF, C. (orgs.). Dimensões Novikoff: um constructo para o ensino um constructo para o ensino-aprendizado da pesquisa. In ROCHA, J.G. e . Desafios da práxis educacional à promoção humana na contemporaneidade. Rio de Janeiro: Espalhafato Comunicação, p. 211-242, 2010. $288 \mathrm{p}$.

NÓVOA, António. Profissão professor. 2. ed. Porto: Porto Editora, 1995.

PAPI, Silmara de Oliveira Gomes. Desenvolvimento profissional de professores: cultura profissional e desafios da profissionalização. Reunião Anual da Associação Nacional de Pós-Graduação e Pesquisa em Educação-ANPED, V. 28, 2005.

PÉREZ GÓMEZ, A. I. A cultura escolar na sociedade neoliberal. Tradução de Ernani Rosa. Porto Alegre: Artmed, 2001.

PÉREZ GÓMEZ, A. I. Compreender o ensino na escola: modelos metodológicos de investigação educativa. In: GIMENO SACRISTÁN, J.; PÉREZ GÓMEZ, A.I. Compreender e transformar o ensino. Tradução de Ernani F. da Fonseca Rosa. $4^{\mathrm{a}}$ ed. Porto Alegre: Artmed, 1998.

PIAGET, Jean; SCHRAMM, Yara; LENARDON, Elzon. O julgamento moral na criança. São Paulo: Mestre Jou, 1977.

RIOS, Terezinha Azerêdo. Ética e competência. 5. ed. São Paulo: Cortez, 1997.

ROMANOWSKI, Joana Paulin e ENS, Romilda Teodora. As pesquisas denominadas do tipo 'Estado da Arte' em educação. In: Revista Diálogo Educacional, Setembro/Dezembro. 2006, Número 19, Volume6. Disponível: http://www.chcbeira.pt/download/As\%20pesquisas\%20denominadas\%20do\%20tipo\%2 0estado\%20da\%20arte.pdf. Acesso: 02/02/2017.

TEIXEIRA, L. H. G. Cultura organizacional da escola, mudança e formação de profissionais do ensino. In: SILVA, R. C. (Org.). Educação para o século XXI: dilemas e perspectivas. Piracicaba: Ed. UNIMEP, 1999. p.101-116.

VARELA, F. Autonomie et Connaissance. Paris: Seuil, 1989. 
VEIGA, Ilma Passos Alencastro. Avanços e equívocos na profissionalização do magistério e a nova LDB. In: VEIGA, Ilma Passos Alencastro; CUNHA, Maria Isabel da (Orgs). Caminhos da profissionalização do magistério. São Paulo: Papirus, 1998. p.75-98. 